\section{German chemicals giant to focus on life sciences}

[MUNICH] The pharmaceutical and chemical company Hoechst, one of the cornerstones of the German chemical industry since the Second World War, is to be restructured with a new focus on life sciences.

Plans to make the change were approved by the company's shareholders at their annual meeting in Frankfurt last week. But attempts to reduce the number of research scientists in a bid to streamline its research are meeting resistance from staff.

Hoechst will discontinue its traditional activities in industrial chemistry by the year 2000. At the same time, research at Hoechst Marion Roussel (HMR), the pharmaceutical company of Hoechst Holding, is to be restricted to core areas of drug design, contracting out other research activities, such as toxicology.

As a result, the number of scientific staff employed in research and development (R\&D) in Frankfurt, HMR's largest research site, will be reduced by about 600 to 1,100 . Similar reductions are planned at its research sites in Romainville, near Paris, and Bridgewater, New Jersey.

Hoechst has been under heavy financial strain in recent years, partly because of its broad spectrum of products and its low productivity in drug design. In the latter area, it has also been criticized for neglecting new methods, such as combinatorial chemistry, high-throughput screening of novel compounds and genomics.

In the past 12 months, Hoechst has been split up into eight separate companies, each with considerable independence within its field of business, but its difficulties have nevertheless continued.

"We cannot be at the top in everything we are doing," Jürgen Dormann, chairman of Hoechst's board of directors, told last week's meeting of shareholders. He said that regional markets for industrial chemistry products, such as standard synthetic materials, are increasingly being met by new Asian competitors and by oil companies.

In contrast to the cost-intensive chemical production of basic materials, biotechnology and genetic engineering would offer new knowledge-based opportunities in drug design, diagnostics, blood products, seeds, veterinary products and food additives, Dormann added.

Hoechst's pharmaceutical company, HMR, is by far the largest of the eight subsidiary companies. Although some describe it as the company's 'heart', it has also become its biggest headache. It spends DM2.4 billion ( $\$ 1.4$ billion) a year on $\mathrm{R} \& \mathrm{D}$, but its profits fell by almost 20 per cent in 1997.

"Productivity at HMR was much too low

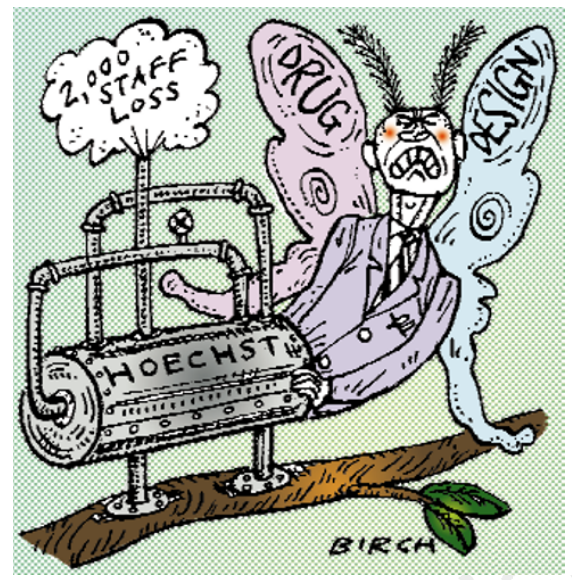

over the past 20 years," said Dormann. He pointed out that, although an average of more than DM10 million a day had been spent on pharmaceutical research over that period, few marketable drugs had been developed.

Furthermore, only 5 per cent of HMR's turnover comes from drugs designed in the past five years, contrasting with an average of 20 per cent for its competitors. So HMR is to cut back on its research activities, confining them to promising projects in areas such as cardiovascular and metabolic disorders, rheumatology, immunology and cancer.

The company aims to reduce the time needed for the introduction of a new drug from 10-15 years to 6-9 years, and to quadruple the share of turnover from recently designed drugs within five years.

The generics part of the business will be of innovative drug design, such as toxicology, will be carried out in cooperation with external companies or research institutes, rather than by HMR's regular scientists.

The R\&D department in Frankfurt will be designated the 'drug innovation and approval' arm, and the scientific staff will be reduced by a third by the end of 1999. HMR's global research budget will then be cut by DM460 million, DM95 million of which will be saved in Germany.

Felicitas Feick, a company spokeswoman, says the nature of HMR's research staff will be changed by taking on young researchers, especially biologists and geneticists.

But researchers at HMR have been opposing the dismissals. Some 7,000 employees protested against the cuts in January, and several hundred have continued to demonstrate in front of the Hoechst headquarters in Frankfurt each Monday.

Hoechst's managers are negotiating with the company's works committee and the unions. A final plan, including proposals for minimizing the staff reductions, will be presented next week.

QuirinSchiermeier sold, and research other than in the core areas
Internet research centre takes Intel inside China

[Tокуо] Intel, one of the world's largest manufacturers of semiconductors, plans to set up a US\$50 million research and development centre in Beijing to conduct research on the use of the Internet and related information technology.

The plan, announced last week, follows recent moves by several other leading multinational companies to set up research and development (R\&D) centres in China's capital. Motorola, Hewlett Packard and IBM are said to be planning similar centres.

Intel plans to invest $\$ 50$ million during the next five years in the centre, which will carry out research with particular relevance to Chinese applications, such as speech recognition. It will also fund projects at China's leading universities and research institutes.

Despite the economic uncertainty in the region, several other multinational companies have also recently set up R\&D centres in China. In April, for example, Procter and Gamble became the first multinational company to set up an R\&D centre at the science park at Tsinghua University, one of China's leading universities, in Beijing.

The previous month, Bell Laboratories announced that it had set up a small R\&D centre on Peking University's campus in Beijing, which will conduct joint research with the university.

"China has a deep pool of talented scientists and engineers, and there is a great opportunity to assemble a world-class team here to do some outstanding research," Andrew Grove, chairman and chief executive officer of Intel, said last week.

Intel's announcement has been welcomed by Chinese academics and researchers, who argue that the establishment of Intel's China Research Center will help to improve the level of fundamental research in high technology in China. "It represents a new trend for foreign investment in China," according to Peiyan Zeng, Chairman of China's State Development Planning Commission.

Some academics say that Intel must contribute actively to China's well-being, and not merely benefit from its resources. The centre should consider its relationship with the Chinese scientific community and provide practical help, argues Jiaxin Wang, deputy director of the State Key Laboratory of Intelligent Technology and Systems.

Research at the centre could stimulate new research at universities, he says. But the centre should promote collaboration with universities, and the company should use part of its profit to support education in China, says Wang, an expert on computeraided pattern recognition, such as the recognition of Chinese characters. Richard Nathan 